\title{
Anatomy of the mitral subvalvular apparatus
}

\author{
Agata Krawczyk-Ożóg, MD, ${ }^{\mathrm{a}, \mathrm{b}}$ Mateusz K. Hołda, MD, PhD, ${ }^{\mathrm{a}, \mathrm{c}}$ Filip Bolechała, MD, PhD, \\ Zbigniew Siudak, MD, PhD, ${ }^{e}$ Danuta Sorysz, MD, PhD, ${ }^{\mathrm{b}}$ Dariusz Dudek, MD, PhD, ${ }^{\mathrm{b}}$ and \\ Wiesława Klimek-Piotrowska, MD, $\mathrm{PhD}^{\mathrm{a}, \mathrm{c}}$
}

\section{ABSTRACT}

Objectives: To characterize morphologic variations in the papillary muscles and tendinous cords of the left ventricle and ventricular zones of the mitral valve leaflets.

Methods: A total of 100 autopsied human hearts from healthy donors with classical mitral valve type were investigated.

Results: In 1 heart, only 1 group of papillary muscles was found, and in the remaining $99 \%$, we could distinguish 2 groups of muscles: Superolateral (SLPM) and inferoseptal papillary muscle (ISPM) groups. The SLPM group had 1 papillary muscle $(75.8 \%), 2$ in $20.2 \%$, and $>3$ in $4.0 \%$. In the ISPM group, the muscle percentages were $38.4 \%, 36.4 \%$, and $25.2 \%$, respectively. The apex of at least 1 papillary muscle was situated higher than the plane of the opened anterior leaflet (AML) in $47.5 \%$ and $50.5 \%$ for the SLPM and ISPM groups, respectively. The number of strut cords arising from the SLPM group was $0(2.0 \%), 1(50.5 \%), 2(33.3 \%), 3(12.1 \%)$, and $4(2.0 \%)$, and from the ISPM group was $0(6.1 \%), 1(52.5 \%), 2(35.4 \%)$, or $3(6.1 \%)$. Cords to left ventricular outflow tract were present in 14 specimens. Muscular cords were found in eight hearts. In all hearts specimens AML had rough and clear zones. The classical zones (rough, clear, and basal) in the posterior mitral leaflet were observed in $38.4 \%$.

Conclusions: There is a high variability in the papillary muscles and tendinous cords in the mitral valve complex. Proper nomenclature, simple classification, and the most common variants for papillary muscle groups and tendinous cords were presented. (J Thorac Cardiovasc Surg 2018;155:2002-10)

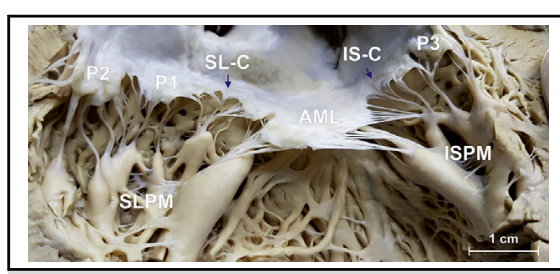

Cadaveric heart specimen showing mitral valve leaflets and the subvalvular apparatus.

\section{Central Message}

This study presents proper nomenclature and simple classification for mitral subvalvular apparatus components. Papillary muscle and tendinous cords morphology was characterized on the basis of 100 hearts.

\section{Perspective}

Knowledge about different variations and morphometry of the subvalvular apparatus components is important for better understanding the pathophysiology of mitral valve apparatus dysfunctions and could help to develop of novel surgical and less invasive strategies of mitral valve disease treatment.

See Editorial Commentary page 2011.
Mitral valve disease has heterogeneous etiology and can be caused by pathological changes in any of the components of the mitral valve apparatus. The mitral valve apparatus is one

From the ${ }^{\mathrm{a}}$ HEART-Heart Embryology and Anatomy Research Team, ${ }^{\mathrm{b}}$ 2nd Department of Cardiology and Cardiovascular Interventions, University Hospital, Institute of Cardiology, ' Department of Anatomy, and ${ }^{\mathrm{d}}$ Department of Forensic Medicine, Jagiellonian University Medical College, Krakow, Poland; and ${ }^{\mathrm{e}}$ Faculty of Medicine and Health Sciences, Jan Kochanowski University in Kielce, Kielce, Poland.

The research was supported by the European Social Fund Operational Programme "Knowledge - Education - Development" under the project "Best of the best! 2.0" (MNISW/2017/98/DIR/NN2). M.K.H. was supported by the Foundation for Polish Science. The funders had no role in the study design, data collection, or analysis, decision to publish, or preparation of the report.

Received for publication Nov 1, 2017; revisions received Dec 5, 2017; accepted for publication Dec 16, 2017; available ahead of print Feb 2, 2018.

Address for reprints: Agata Krawczyk-Ożóg, MD, 2nd Department of Cardiology and Cardiovascular Interventions, Kopernika 17, Cracow 31-501, Poland (E-mail: krawczyk.ozog@gmail.com).

$0022-5223 / \$ 36.00$

Copyright (c) 2017 by The American Association for Thoracic Surgery

https://doi.org/10.1016/j.jtcvs.2017.12.061 of the most complex mechanical structures within the human body and consists of 2 main components: (1) the mitral valve leaflets and commissures, and (2) the subvalvular apparatus, which consists of papillary muscles and tendinous cords. ${ }^{1,2}$ Mitral valve papillary muscles are located in the left ventricle between the apex and its middle third and develop as a result of condensation of trabeculae and delamination of ventricular myocardium. ${ }^{3}$ Tendinous cords are collagenous and elastin cord-like tendons that connect the papillary muscles to the ventricular surface of the valve leaflets. Several morphological types of the tendinous cords might be distinguished. The basic role of

Scanning this QR code will take you to the article title page. 


\author{
Abbreviations and Acronyms \\ $\mathrm{AML}=$ anterior mitral leaflet \\ ISPM $=$ inferoseptal papillary muscle \\ LVOT $=$ left ventricular outflow tract \\ P1 = lateral scallop of the posterior mitral leaflet \\ P2 = middle scallop of the posterior mitral \\ leaflet \\ P3 = medial scallop of the posterior mitral \\ leaflet \\ PML = posterior mitral leaflet \\ SLPM $=$ superolateral papillary muscle
}

the subvalvular apparatus is to enable proper closure of the mitral valve leaflets and prevent inversion or prolapse of the valve upon systole. ${ }^{4}$ Dysfunction of the papillary muscles are more often caused by chronic or sudden ischemia and can lead to significant mitral valve regurgitation and finally to heart failure. In addition, tendinous cord damage cause complications that lead to damage of heart function.

Knowledge about different variations and morphometry of the subvalvular apparatus components is important for better understanding of mitral valve apparatus dysfunction; additional knowledge can help to develop and improve different treatment methods. ${ }^{5,6}$ Available studies have presented several types of papillary muscles and tendinous cord classifications. ${ }^{7-15}$ However, their results are inconsistent and usually clinically insignificant. In this study we sought to characterize papillary muscle morphology. The second aim of current study was to describe tendinous cord morphology, and their types, lengths, and numbers. Finally, we also wanted to characterize the ventricular surface of the mitral valve leaflets and their zones that are created by the tendinous cord attachments.

\section{METHODS}

\section{Study Material}

A total of 100 autopsied human hearts from Caucasian individuals with classical mitral valve type were included in this study $(32 \%$ female, mean age $47.9 \pm 19.1$ years, mean body mass index was $26.6 \pm 4.1$, and mean body surface area was $1.9 \pm 0.2 \mathrm{~m}^{2}$ ). The classical mitral valve type was defined as a valve with 2 main leaflets consisting of a single anterior mitral leaflet (AML) and posterior mitral leaflet (PML) that is composed of 3 scallops: lateral (P1), middle (P2) and medial (P3); both leaflets are connected with commissures and have no abnormalities in the anatomical structure. ${ }^{1}$

Samples were collected during routine forensic medical autopsies performed between July 2013 and June 2016. All analyzed specimens had no severe anatomical defects, previous heart surgeries, heart trauma, evidence of severe macroscopic heart or vascular system pathologies, macroscopic signs of cadaver decomposition found during autopsy, and any valve disease or arrhythmia in medical history. The reasons for death mainly included suicide, murders, and traffic and home accidents. This study was approved by the Bioethical Committee of Jagiellonian University (number 22.6120.253.2016). Our Bioethical Committee waived the need for consent from donors. We collected hearts only from deceased persons who did not express objection, when alive, and only if the family did not express objection.

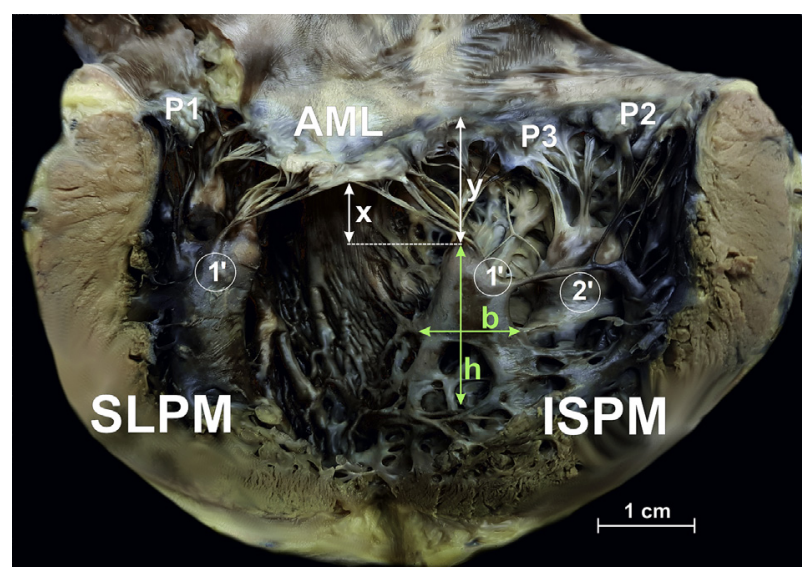

FIGURE 1. Photograph showing a cadaveric heart specimen. View of the superolateral papillary muscle $(S L P M)$ and inferoseptal papillary muscle $(I S P M)$ groups with marked individual muscles $\left(1^{\prime}\right.$ and $\left.2^{\prime}\right) . P 1, P 2, P 3$, Posterior mitral leaflet scallops; $A M L$, anterior mitral leaflet; $x$, distance from the apex to the opened anterior mitral leaflet; $y$, distance from the apex to the mitral annulus; $b$, width of the base; $h$, height.

\section{Dissection and Measurements}

The hearts were dissected and weighed before fixation by immersion in $10 \%$ paraformaldehyde solution for a maximum of 2 months until the time of measurement. ${ }^{16}$ The left atrium was opened in a routine way. The mitral valve was opened between the P1 and P2 scallops and the left ventricle wall was then cut in such way so that the papillary muscle was not cut. If necessary, accessory cuttings were performed for better visualization of the studied region.

First, groups of the papillary muscles were identified: (1) superolateral papillary muscles (SLPMs), and (2) inferoseptal papillary muscles (ISPMs). The SLPM group, described also mistakenly as an anterolateral papillary muscle, is located between the lateral and superior left ventricle wall. The ISPM, which has been mistakenly named as a posteromedial, is located at the border between the inferior left ventricle wall and interventricular septum. ${ }^{17,18}$ To avoid mistakes in identification of the groups of the papillary muscles tendinous cord attachment is helpful. Tendinous cords arising from the SLPM group usually attach to the lateral part of the AML, superolateral commissure, P1, and half of the P2 scallop of the PML whereas those originating from ISPMs terminate in the medial part of the AML, inferoseptal commissure, P3, and half of the P2 scallop of the PML (Figure 1). To show the arrangement of the papillary muscle groups within the left ventricle, the distances from the geometrical center of papillary muscle groups to the center point of the left ventricular outflow tract (LVOT) in addition to the distance between the geometrical centers of the papillary muscles groups along the free wall of the left ventricle were measured. The distances between the edges of papillary muscle groups along the left ventricle free wall at the level of the middle of their attachment to the left ventricle were also measured.

Moreover, individual papillary muscles were identified between the SLPM and ISPM groups. We defined the single papillary muscle as the muscle with its own origin, base, trunk, and one or more apices (or head/ bell). The individual muscles were numbered in order from the LVOT toward the left ventricle free wall $\left(1^{\prime}\right.$ to $\left.4^{\prime}\right)$. The number of papillary muscles in each group was noted. Next, the number of apices in each papillary muscle was counted. The height of the individual papillary muscle attachment to the left ventricle wall, and the height of the individual papillary muscle from the origin/base (lowest point) to the highest apex in addition to the maximum height for the whole muscle group was measured. Also, the width of the base of the individual papillary muscle and whole papillary 

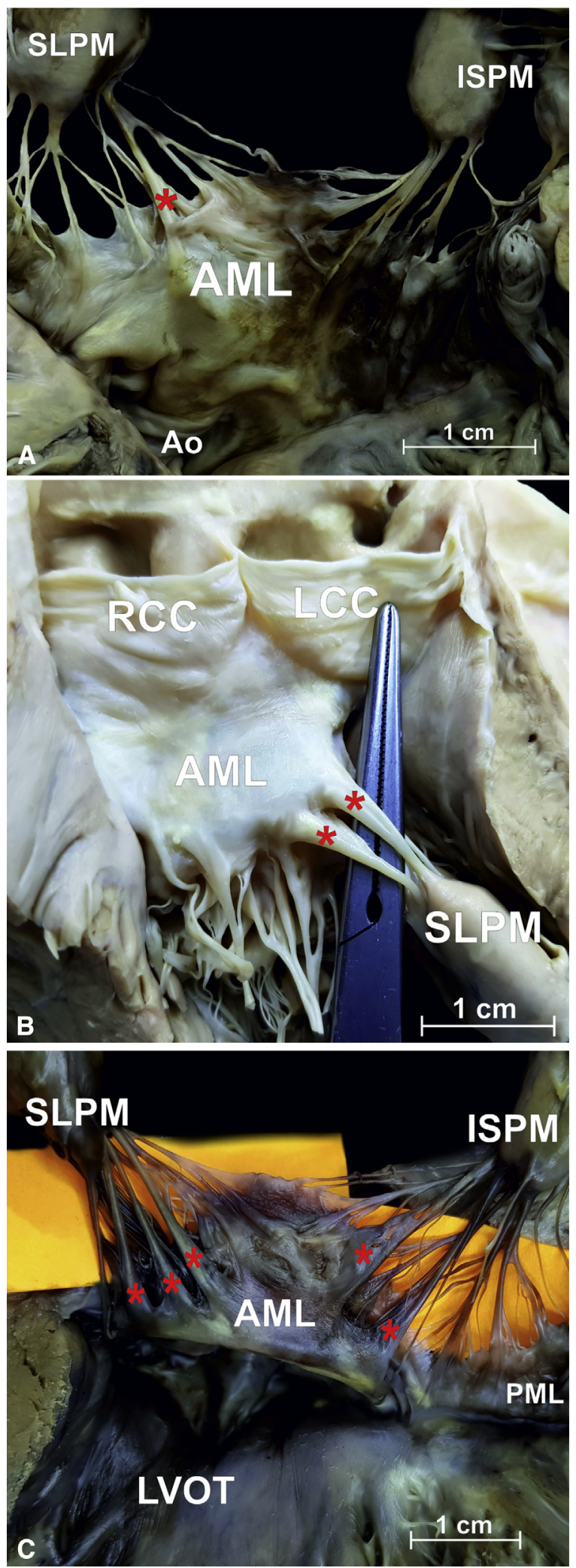

FIGURE 2. Photograph showing ventricular surface of the anterior mitral leaflet $(A M L)$ with marked strut cords $(*)$. A, One strut cord from the superolateral papillary muscle (SLPM) group and no strut cords from the muscle group was measured at the level of their geometrical centers. Finally, the distance from the highest apex of the papillary muscle to the mitral annulus plane and to the plane formed by the tip of opened AML in addition to the distance from apex to the left ventricle wall surface were assessed (Figure 1).

Next, we studied the numbers and types of tendinous cords originating from the SLPM and ISPM groups and patterns of their attachments to the leaflets. True cords were defined as cords that arose from the papillary muscle (root) and were inserted into any part of the valvular leaflet or commissures, and false cords were defined as cords that originated from papillary muscles or left ventricle wall and were not attached to the leaflets or commissures. Seven specific types of tendinous cords were defined:

- Rough zone cords: "standard," true, and most common cords arising from apex of the papillary muscle or its margin and inserted into the leaflet (rough zone);

- Strut cords: the strongest and toughest among rough zone cords, arising from the tip of the papillary muscle group and attached to the central parts of rough zone (Figure 2);

- Muscular cords: fleshy and the thickest cords arising from papillary muscles attached to any part of mitral valve leaflets (Figure 3, A);

- Indentation's cords: inserting to the free edges of the PML to its indentations between scallops, arising from the papillary muscle usually as a single stem but branching out in a manner resembling the struts of a fan before insertion;

- Commissural cords: originating solely from the respective papillary muscle located beneath the commissure and running as a single stem that branches radially (in a fan-shaped fashion; Figure 3, C);

- Cords to the LVOT: false cords, recognized on the basis of their attachment to the left ventricle septal wall in the LVOT area, arising from the papillary muscle (Figure 3, B); and

- Basal cords (or tertiary cords): neither true nor false cords, arising directly from the left ventricle wall or from small trabeculae carneae and inserting to the basal zone on the ventricular surface of the leaflet, close to the hinge line (Figure 3, D). ${ }^{12,15,19}$

The total number and length of the strut, muscular, indentations, commissural, basal, and LVOT cords were assessed.

Finally, tendinous cords were cut off from their papillary muscle origin to visualize the ventricular surface of the mitral leaflets. Three possible zones were defined as previously described: (1) rough zone (the border area where tendinous cords attach), (2) clear zone (the smooth area extending from the rough zone toward the hinge line, without any attachment of the tendinous cords), and (3) basal zone (area at which basal cords are inserted, separating the clear zone from the hinge line of the leaflet). ${ }^{20,21}$ The height of all zones was measured in the central part of AML and in the central part of the PML P2 scallop (Figure 4).

All measurements were obtained by using $0.03-\mathrm{mm}$ precision electronic calipers (Yato, YT-7201; TOYA, S.A., Wroclaw, Poland) and were performed by 2 independent researchers to reduce potential bias. The mean of the 2 values was calculated. If the measurement differences between the researchers exceeded $10 \%$, both measurements were repeated.

\section{Statistical Analysis}

The data are presented as mean values and the corresponding SDs or percentages as well as median with interquartile range. The ShapiroWilk test was used to determine if the quantitative data were normally

inferoseptal papillary muscle (ISPM) group. B, Two strut cords arising from the SLPM group. C, Two strut cords arising from the ISPM group and 3 from the SLPM group. Ao, Aorta; $R C C$, right coronary cusp; $L C C$, left coronary cusp; $L V O T$, left ventricular outflow tract; $P M L$, posterior mitral leaflet. 

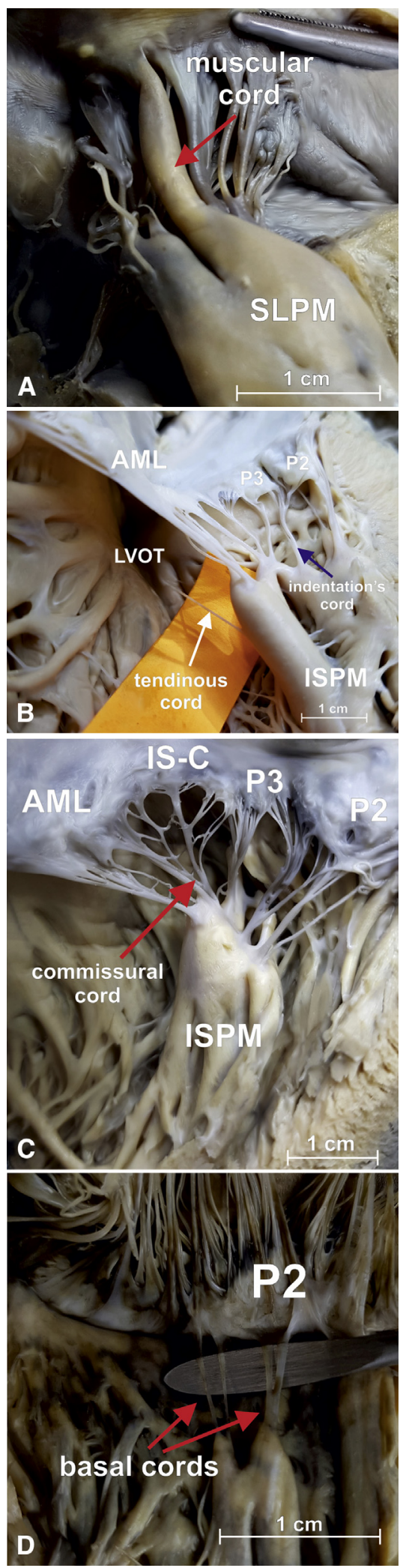

FIGURE 3. Photographs showing cadaveric heart specimen with marked various kind of tendinous cords. A, Muscular cord; B, cord to the left ventricular outflow tract (LVOT); C, commissural cord; and D, basal cords. distributed. To verify homogeneity of variance, the Levene test was performed. We also used the Student $t$ tests and the Mann-Whitney $U$ tests for statistical comparisons. Correlation coefficients were calculated to measure the statistical dependence between the measured parameters. We performed statistical analyses with STATISTICA version 13.1 (StatSoft Inc, Tulsa, Okla). $P<.05$ was considered to be statistically significant.

\section{RESULTS}

In the study group, one heart with only one group of papillary muscles was found without the possibility to distinguish between the SLPM and ISPM. This heart was excluded from further analysis. The mean heart weight was $437.2 \pm 101.0 \mathrm{~g}$, and it was higher for male than female hearts $(456.1 \pm 98.8$ vs $365.6 \pm 75.7 \mathrm{~g} ; P<.0001)$.

The mean distance between the center of both papillary muscle groups along the left atrial septal wall (through the LVOT) was $58.8 \pm 12.0 \mathrm{~mm}$, from the SLPM group center to the LVOT center $28.6 \pm 7.3 \mathrm{~mm}$, and from the ISPM group center to the LVOT center $29.7 \pm 8.5 \mathrm{~mm}$. The mean distance between the centers of both papillary muscle groups along the left ventricle free wall was $20.9 \pm 9.2 \mathrm{~mm}$. In $34.3 \%$ of the study hearts, the SLPM and ISPM groups adhered to each other, and in the remaining cases, the mean distance between the edges of both groups was $10.0 \pm 6.9 \mathrm{~mm}$. Both groups were connected by false cords in almost all cases $(95.0 \%$ ), and in $40.4 \%$ of the cases, linking muscular bridges were observed.

In $75.8 \%$ of the cases, the SLPM group had 1 papillary muscle, in $20.2 \% 2$ muscles, in $3.0 \% 3$ muscles, and in 1 case 4 papillary muscles were found. In the ISPM group, the percentages of papillary muscles were $38.4 \%, 36.4 \%$, $23.2 \%$, and $2.0 \%$, respectively. Table 1 shows a detailed distribution of the number of papillary muscles in the SLPM and ISPM groups. The mean height for the whole SLPM group was $32.3 \pm 5.7 \mathrm{~mm}$ and for the ISPM group $31.1 \pm 4.9 \mathrm{~mm}$. The base width was smaller for the SLPM than the ISPM group (16.8 \pm 5.1 vs $22.3 \pm 6.9 \mathrm{~mm} ; P<.0001)$. There were significant differences in base width for the entire SLPM as well as ISPM groups, which depended on the number of individual papillary muscles forming the groups that gradually increased with the number of papillary muscles $(P<.05)$. The height and base width for the entire SLPM group were correlated with age $(r=-0.25 ; P=.02$ and $r=0.27 ; P=.01$, respectively).

Table 2 provides morphometric measurement results for individual papillary muscles. The apex of at least 1 papillary muscle was situated higher than the plane of the opened anterior leaflet in $47.5 \%$ of the SLPM group (in $87.2 \%$, only 1 papillary muscle; in $8.5 \%, 2$ papillary muscles;

SLPM, Superolateral papillary muscle; $A M L$, anterior mitral leaflet; $I S P M$, inferoseptal papillary muscles; $I S$ - $C$, inferoseptal commissure; $P 2$, $P 3$, posterior mitral leaflet scallops. 
and in $4.3 \%, 3$ papillary muscles), and $50.5 \%$ for the ISPM group (in $72.0 \%$, only 1 papillary muscle and in $28.0 \%, 2$ or more). The $1^{\prime}$ SLPM had significantly more apices and was larger than the $2^{\prime}$ and $3^{\prime}$ muscles in this group; in addition, more true tendinous cords roots were observed for the $1^{\prime}$ papillary muscle, and the same finding was observed for ISPM group $(P<.0001)$.

Table 3 provides details about the numbers of roots and attachments of true tendinous cords and number of false cords from each papillary muscle group, which was not surprising because the number of cords branching from the number of the attachments was significantly larger than the number of roots. Significantly more true cords were attached to the PML than to the AML $(39.9 \pm 10.9$ vs $29.9 \pm 6.5 ; P<.0001)$. We observed significantly more false cords originating from the ISPM than the SLPM group $(P<.0001)$. This was also found for false cords to the LVOT (14 cases, $14.1 \%$ ) that originated in 2 specimens from the SLPM and in 12 hearts from the ISPM. So-called LVOT cords were thin and long (21$37 \mathrm{~mm}$ ) and attached to the septal wall of the left ventricle in the area of the LVOT (6-25 mm below the aortic valve; Figure 3, B).

Strut cords were identified only for AML (Figure 2). The number of strut cords originating from the ISPM group was $0(6.1 \%), 1(52.5 \%), 2(35.4 \%)$, or $3(6.1 \%)$ with a mean length of $21.4 \pm 4.6 \mathrm{~mm}$. The amount of strut cords arising from the SLPM group was $0(2.0 \%), 1(50.5 \%), 2(33.3 \%)$, $3(12.1 \%)$, or $4(2.0 \%)$ with a mean length of $20.9 \pm 4.2 \mathrm{~mm}$.

Muscular cords (Figure 3, $A$ ) were found in 8 hearts (total 11 cords, 8 from the SLPM and 3 from the ISPM groups) with a mean length of $15.1 \pm 6.2 \mathrm{~mm}$ and attachment to the AML in 7 cases, PML in 3 cases, and superolateral commissure in 1 case. The indentation chordae between the P1 and P2 and between the P2 and P3 scallops were identified in all hearts with mean lengths of $15.5 \pm 4.0$ and $16.1 \pm 3.1 \mathrm{~mm}$, respectively.

The superolateral commissural cord was identified in all hearts, and in $24.2 \%$ cases it was attached exclusively to the commissure. In $51.5 \%$ of the hearts, the cord gave branches to the AML and the P1 PML, in $13.1 \%$ only to the P1 PML, and in $11.1 \%$ only to the AML. The mean length of the main stem of the superolateral commissural cord was $12.2 \pm 3.3 \mathrm{~mm}$, which correlated with the body mass index $(r=0.31 ; P=.01)$ and heart weight $(r=0.3 ; P=.01)$. The inferoseptal commissural cord was identified in all cases, but $8.1 \%$ did have a single attachment, in $74.7 \%$ it branched to the AML and the P3 PML, in 5.1\% only to the P3 PML, and in $12.1 \%$ only to the AML. The mean length of the inferoseptal commissural cord main stem was $14.1 \pm 3.9 \mathrm{~mm}$.

In all heart specimens, the AML has only 2 zones: rough and clear (Figure 4,A). Clear zones were statistically significantly larger than rough zones $(14.1 \pm 2.9$ vs $9.0 \pm 2.2 \mathrm{~mm} ; P<.0001)$ and were correlated with the age and heart weight $(r=0.25 ; P=.02$ and $r=0.26$; $P=.02$, respectively). The classical zones in the PML (rough, clear, and basal) were described in only $38.4 \%$ of the hearts (Figure 4, B). For the classical 3-zone leaflet, the mean height for rough, clear, and basal zones were $8.9 \pm 2.6,3.0 \pm 1.0$, and $2.2 \pm 1.7 \mathrm{~mm}$, respectively $(P<.05)$. In the remaining cases, we observed PML with 2 zones (rough and clear $[9.1 \pm 2.2$ and $4.1 \pm 1.4 \mathrm{~mm}$, respectively]), in $43.4 \%$ it was only rough $(11.6 \pm 2.9 \mathrm{~mm})$, and basal $(2.4 \pm 0.9 \mathrm{~mm})$ in $11.1 \%$. In $7.1 \%$ only 1 rough zone $(10.9 \pm 2.7 \mathrm{~mm})$ was present. The clear zone was best seen in the P2 scallop in contrast to $\mathrm{P} 1$ and P3, in which it did not exist in most cases. Basal cords were found in 49 hearts (Figures $3, D$ and $4, B$ ) and were attached only to P2 scallops (30 hearts, $61.2 \%$ ), in 5 specimens $(10.2 \%)$ only to $\mathrm{P} 1$, and in 3 cases $(6.1 \%)$ only to the P3 scallop. In 5 hearts $(10.2 \%)$ basal cords were attached to the P2 and P1 scallops, and in 2 cases $(4.1 \%)$ to the P2 and P3 scallops. In 2 cases, we found single basal cords attached to the AML, and basal cords to commissures were also found in 2 hearts.

\section{DISCUSSION}

As expected, the current study confirmed that the presence of 2 separate papillary muscle groups is the most common variant of mitral valve apparatus morphology. We want to emphasize, however, proper terminology associated with papillary muscles and tendinous cords, is incorrectly used in most publications and daily clinical practice, ${ }^{5,7-10,12,15,19,20,22-25}$ because we observed the papillary muscle is not always a single muscle, but rather a conglomerate of several connected muscles. $7,9,10,22,23$ Therefore, we recommend using the term, papillary muscle group, as a more relevant term. The second issue is related to the location of papillary muscle groups. The general rule in the anatomy is to describe organs and structures as seen with the individual standing upright in the anatomic position. Unfortunately, the heart is widely described in the Valentine fashion, which is incorrect. Thus, the papillary muscle groups are incorrectly described as being located posteromedial and anterolateral, which in fact should be inferoseptal and superolateral, respectively.

In the current study, which is in agreement with previous literature, the base of the papillary muscle groups were localized within the left ventricle close together, and in $34.3 \%$ they adhered to each other. ${ }^{5}$ Different connections between papillary muscle groups (false cords or muscular bridges) were observed in all cases. The connection between 2 groups more often takes place on the left ventricle free wall, whereas the LVOT was in almost in all cases free from papillary muscles. 

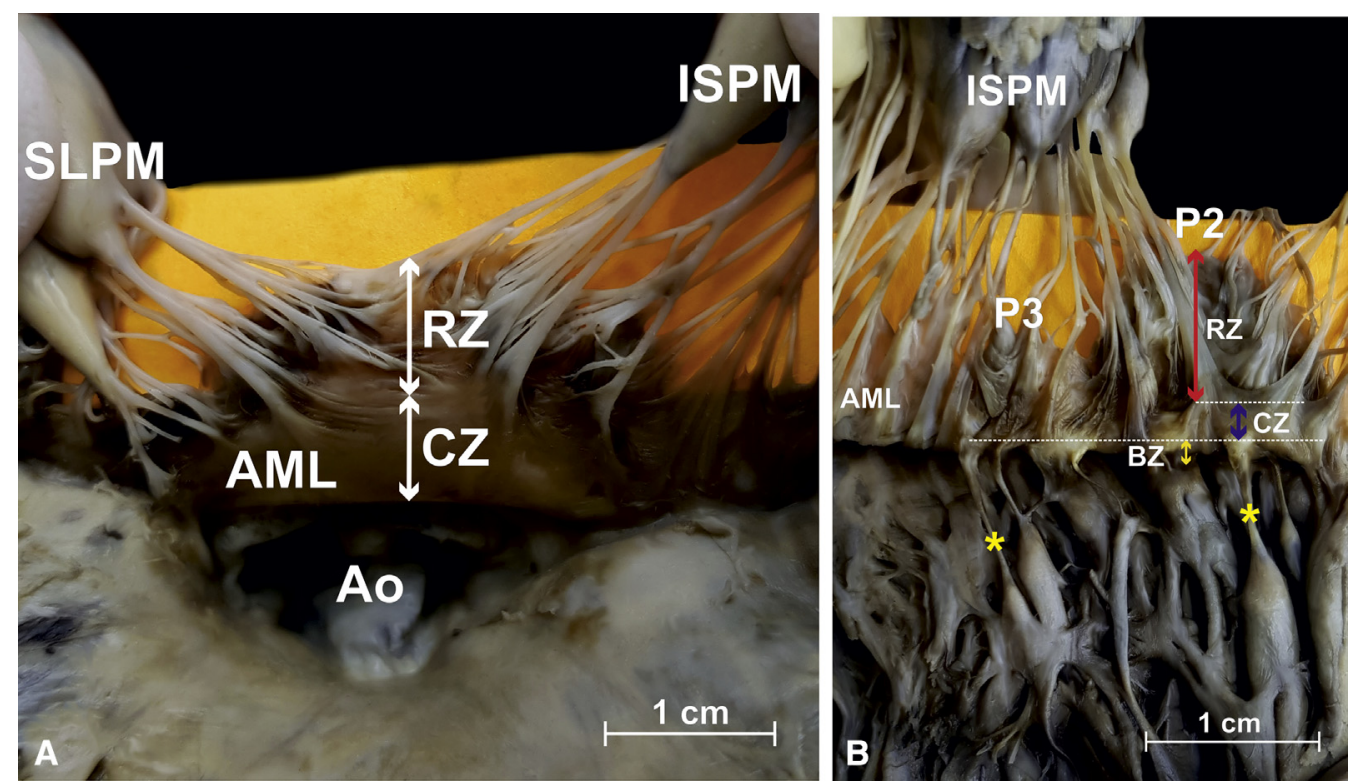

FIGURE 4. Photographs showing cadaveric heart specimens, the zones of both mitral valve leaflets on their ventricular surfaces. The presence and measurement of height particular zones were performed on the central part of anterior mitral leaflet and on $\mathrm{P} 2$ scallop of the posterior mitral leaflet. A, Rough $(R Z)$ and clear $(C Z)$ zones of anterior mitral leaflet $(A M L)$. B, RZ, CZ, and basal $(B Z)$ zones with marked basal cords $(*)$ of the posterior mitral leaflet (PML). $I S P M$, Inferoseptal papillary muscles; $S L P M$, superolateral papillary muscles; $A o$, aorta; $P 2, P 3$, posterior mitral leaflet scallops.

In previous studies, we can find some complex classifications of the papillary muscle groups that are on the basis of shapes, sizes, and number of muscles/heads/bellies, and their mutual arrangements within groups ${ }^{9,10,22}$ or the ways that the individual papillary muscles relate to the leaflets through cords. ${ }^{7,11}$ We tried to adjust some of those classifications in the current study; however, it was difficult, highly subjective, and huge inter- and intravariability was observed. Because of the enormous morphological variability of the papillary muscle groups that are so unique as fingerprints and the fact that morphological and clinical significance of such classifications is questionable, we abandoned attempts to create any classification of the papillary muscles. ${ }^{26}$

There is a simple explanation, related to their development, as to why papillary muscle groups and tendinous cords are so variable. As mentioned before, the subvalvular apparatus is formed as a result of delamination of the ventricular musculature. Aberrations in this process would lead to muscle persistence to a varying extent. ${ }^{10}$ One of the examples of distorted delamination is the occurrence of muscular cords, the presence of which is undesirable because they could easily degenerate and produce leaflet restriction. ${ }^{27}$ Other important observations from our study, which might be also related to the impaired delamination, was that in approximately $50 \%$ of cases the muscle apex might be located higher than the plane of the leaflet tip and situated between left ventricle wall and opened leaflet. This might have some negative implications for blood flow (valve obstruction), transcatheter repair techniques, or implantation of the prosthetic mitral valve. Interposed apex of the papillary muscle might interfere with the function of the implanted mitral valve. Moreover, this variant might predispose to the anomalous insertion of papillary muscles directly into the AML, which is observed in approximately $15 \%$ of mitral valves removed from patients with obstructive hypertrophic cardiomyopathy. ${ }^{28}$

TABLE 1. Number of the papillary muscle in superolateral and inferoseptal groups $(\mathbf{n}=99)$

\begin{tabular}{|c|c|c|c|c|c|c|}
\hline & \multirow[b]{2}{*}{ Number of papillary muscle } & \multicolumn{4}{|c|}{ Superolateral group of papillary muscles } & \multirow[b]{2}{*}{ Total } \\
\hline & & 1 & 2 & 3 & 4 & \\
\hline \multirow{5}{*}{ Inferoseptal group of papillary muscles } & 1 & 33 & 3 & 2 & 0 & 38 \\
\hline & 2 & 23 & 11 & 1 & 1 & 36 \\
\hline & 3 & 18 & 5 & 0 & 0 & 23 \\
\hline & 4 & 1 & 1 & 0 & 0 & 2 \\
\hline & Total & 75 & 20 & 3 & 1 & 99 \\
\hline
\end{tabular}


TABLE 2. Results of obtained morphometric measurements (mean \pm SD) of the individual papillary muscles

\begin{tabular}{|c|c|c|c|c|c|c|c|c|}
\hline \multirow{2}{*}{$\begin{array}{l}\text { Dimension } \\
\text { Papillary muscle }\end{array}$} & \multicolumn{4}{|c|}{ Superolateral papillary muscle group } & \multicolumn{4}{|c|}{ Inferoseptal papillary muscle group } \\
\hline & $1^{\prime}$ & $2^{\prime}$ & $3^{\prime}$ & $4^{\prime}$ & $1^{\prime}$ & $2^{\prime}$ & $3^{\prime}$ & $4^{\prime}$ \\
\hline $\mathrm{N}$ & 75 & 20 & 3 & 1 & 38 & 36 & 23 & 2 \\
\hline Number of apexes in papillary muscle & $3.2 \pm 1.0$ & $1.3 \pm 0.6$ & $1.3 \pm 0.5$ & 3.0 & $2.8 \pm 1.1$ & $1.6 \pm 0.8$ & $1.3 \pm 0.6$ & 2.0 \\
\hline Height, mm & $32.1 \pm 5.9$ & $18.1 \pm 7.1$ & $17.2 \pm 5.9$ & 21.4 & $30.5 \pm 5.6$ & $21.1 \pm 7.1$ & $21.7 \pm 7.9$ & $20.4 \pm 4.9$ \\
\hline Width, mm & $14.1 \pm 2.9$ & $6.3 \pm 2.6$ & $5.9 \pm 2.4$ & 7.6 & $12.9 \pm 4.4$ & $8.4 \pm 3.0$ & $7.3 \pm 2.2$ & $6.1 \pm 2.5$ \\
\hline $\begin{array}{l}\text { Height of the attachment to the left ventricle wall, } \\
\mathrm{mm}\end{array}$ & $20.9 \pm 6.1$ & $11.2 \pm 4.9$ & $9.7 \pm 3.5$ & 12.9 & $18.6 \pm 5.4$ & $13.5 \pm 5.3$ & $12.5 \pm 5.3$ & $12.5 \pm 4.9$ \\
\hline $\begin{array}{l}\text { Distance from highest apex to the left ventricle } \\
\text { wall, } \mathrm{mm}\end{array}$ & $2.6 \pm 1.7$ & $1.8 \pm 1.4$ & $1.3 \pm 1.2$ & 0.5 & $3.4 \pm 2.4$ & $2.7 \pm 2.1$ & $2.6 \pm 1.2$ & $3.1 \pm 0.1$ \\
\hline $\begin{array}{l}\text { Distance from apex to the mitral annulus plane, } \\
\mathrm{mm}\end{array}$ & $18.3 \pm 4.4$ & $20.0 \pm 4.1$ & $22.0 \pm 3.4$ & 19.3 & $20.6 \pm 4.9$ & $20.7 \pm 4.3$ & $22.5 \pm 4.0$ & $20.9 \pm 2.9$ \\
\hline \multicolumn{9}{|c|}{ Distance from highest apex to the plane formed by the tip of opened AML } \\
\hline When the apex is located below this plane, $\mathrm{mm}$ & $5.0 \pm 2.7$ & $6.2 \pm 3.3$ & $2.5 \pm 2.1$ & 1.8 & $4.7 \pm 2.4$ & $5.3 \pm 3.5$ & $3.8 \pm 1.6$ & $4.0 \pm 3.1$ \\
\hline When the apex is located above this plane, $\mathrm{mm}$ & $4.9 \pm 3.2$ & $4.1 \pm 2.3$ & $5.5 \pm 4.9$ & - & $4.3 \pm 2.6$ & $4.4 \pm 2.3$ & $2.2 \pm 1.3$ & 4.0 \\
\hline Number of true tendinous cords roots & $10.4 \pm 3.6$ & $3.5 \pm 2.4$ & $2.3 \pm 1.5$ & 4.0 & $9.0 \pm 3.7$ & $4.1 \pm 1.8$ & $3.0 \pm 1.4$ & $4.0 \pm 1.4$ \\
\hline
\end{tabular}

$\overline{A M L}$, Anterior mitral leaflet.

The number of papillary muscles forming the group might also be clinically important. An ischemic event affecting the base of the papillary muscle will render all originating cords dysfunctional, leading to acute mitral regurgitation. Papillary muscle infarction in the patient with multiple papillary muscles damages the subvalvular apparatus to a lesser extent and will cause a smaller hemodynamic effect. ${ }^{9}$ However, because the size of the papillary muscle group increases gradually with the number of individual muscles, groups with more muscles might contribute to the LVOT obstruction, especially when it is accompanied with progression of hypertrophic cardiomyopathy. ${ }^{29}$

A lot of tendinous cord classifications have also been proposed. ${ }^{12,14,15}$ These classifications are usually very extensive; for example, Gunnal et al presented 21 different types of cords and classified them into 6 different types according to the origin, attachments, insertion, distribution, branching patterns, and gross structure. ${ }^{12}$ In our opinion, such a multidirectional approach is not clear and can cause many inaccuracies. Thus, we propose to divide cords into 3 types: (1) true cords, which arise from the apex of the papillary muscles to mitral leaflets or commissures and among which rough zone, strut, muscular, indentation, and commissural cords should be distinguished, (2) false cords, which originate from papillary muscles or the left ventricle wall and are not attached to the leaflets or commissures among which cords to the LVOT might appear, and (3) tertiary cords (basal cords), which are mainly associated with PML and are present in approximately $50 \%$ of hearts. We should also avoid using the term, cleft cords, for cords inserted between scallops because the term cleft is exclusively reserved for

TABLE 3. Number of true and false tendinous cords $(\mathbf{N}=99)$

\begin{tabular}{|c|c|c|c|c|}
\hline Tendinous cords & Mean & SD & Minimum & Maximum \\
\hline Number of the true tendinous cords roots from the SLPM group to the PML & 6.1 & 2.3 & 2 & 14 \\
\hline Number of the tendinous cords attachments on the PML from the SLPM group & 19.1 & 6.3 & 6 & 37 \\
\hline Number of the true tendinous cords roots from the SLPM group to the AML & 5.4 & 1.7 & 1 & 11 \\
\hline Number of the tendinous cords attachments on the AML from the SLPM group & 15.1 & 4.2 & 6 & 28 \\
\hline Number of false cords from the SLPM group & 3.5 & 2.2 & 0 & 11 \\
\hline Number of the true tendinous cords roots from the ISPM group to the PML & 7.0 & 2.1 & 2 & 13 \\
\hline Number of the tendinous cords attachments on the PML from the ISPM group & 21.5 & 6.7 & 8 & 40 \\
\hline Number of the true tendinous cords roots from the ISPM group to the AML & 6.1 & 2.0 & 3 & 11 \\
\hline Number of the tendinous cords attachments on the AML from the ISPM group & 15.2 & 3.6 & 8 & 27 \\
\hline Number of false cords from the ISPM group & 5.4 & 2.7 & 0 & 12 \\
\hline
\end{tabular}

$S D$, Standard deviation; SLPM, superolateral papillary muscle; $P M L$, posterior mitral leaflet; $A M L$, anterior mitral leaflet; $I S P M$, inferoseptal papillary muscle. 
congenital, pathological leaflet splits, and the term, indentation, should be used to define any cleavage in mitral valve leaflets; therefore indentation cords, not cleft cords, are present in all normal hearts. ${ }^{1}$

Strut cords, described in the literature as 2 in number, provide resistance to the AML during systole thus preventing prolapse. The strut cords have no direct influence on valve coaptation, but they have an important role in the tunnel-shaped configuration of the valve at the inflow and outflow tracts. ${ }^{13,15,30,31}$ The morphology of strut cords (characteristic localization, increased thickness, and triangular leaflet-strut chordae transition zone) is responsible for normal, nonhomogeneous motion of the AML. ${ }^{32}$ In this study we found that the number of strut cords is highly variable, and in some cases, there are no strut cords arising from 1 or both papillary muscles groups (Figure 2). Lack of symmetry in the numbers of strut cords could potentially cause decreased control of the AML motion during the cardiac cycle and predispose to regurgitation.

The commissural cords are detected in all hearts, 1 for each commissure. They are dedicated to valve closure through the coaptation of the valve segments. ${ }^{31}$ Commissures, which anatomically separate 2 leaflets, should not be confused with clefts, which are congenital, pathologic splits that reach the mitral annulus and are not connected with the tendinous cords to the papillary muscle. ${ }^{1}$ A cleft mitral valve usually occurs in the setting of an ostium primum atrial septal defect and is associated with mitral regurgitation.

In $14 \%$ of hearts false cords to the LVOT were seen and they do not seem to have a physiological role. However, the presence of such cords might significantly impede transcatheter procedures related to the aortic valve. Unfortunately, they are too thin to be imaged using standard techniques.

The main limitation of this study was the potential changes in size and shape of the heart that might have occurred after formaldehyde fixation, which might give bias in the measurements. However, previous studies have shown that the measurements after fixation in $10 \%$ paraformaldehyde are nonsignificant and similar to those before fixation. ${ }^{16}$ Because the mitral valve complex has a dynamic geometry, we cannot predict changes in dimensions within the cardiac cycle.

\section{CONCLUSIONS}

There is a high variability in the papillary muscles and tendinous cords in the mitral valve complex. Proper nomenclature, simple classification, and the most common variants for papillary muscle groups and tendinous cords were presented in this report.

\section{Conflict of Interest Statement}

Authors have nothing to disclose with regard to commercial support.

\section{References}

1. Krawczyk-Ozóg A, Hołda MK, Sorysz D, Koziej M, Siudak Z, Dudek D, et al. Morphologic variability of the mitral valve leaflets. J Thorac Cardiovasc Surg. 2017; 154:1927-35

2. Quill JL, Hill AJ, Laske TG, Alfieri O, Iaizzo PA. Mitral leaflet anatomy revisited. J Thorac Cardiovasc Surg. 2009;137:1077-81.

3. Oosthoek PW, Wenink AC, Wisse LJ, Gittenberger-de Groot AC. Development of the papillary muscles of the mitral valve: morphogenetic background of parachute-like asymmetric mitral valves and other mitral valve anomalies. J Thorac Cardiovasc Surg. 1998;116:36-46.

4. Marzilli M, Sabbah HN, Lee T, Stein PD. Role of the papillary muscle in opening and closure of the mitral valve. Am J Physiol. 1980;238:H348-54.

5. Ho SY. Anatomy of the mitral valve. Heart. 2002;88:iv5-10.

6. Bateman MG, Quill JL, Hill AJ, Iaizzo PA. The clinical anatomy and pathology of the human atrioventricular valves: implications for repair or replacement. $J$ Cardiovasc Transl Res. 2013:6:155-65.

7. Berdajs D, Lajos P, Turina MI. A new classification of the mitral papillary muscle. Med Sci Monit. 2005;11:BR18-21.

8. Roberts WC. Left ventricular papillary muscles causing them to be abnormal. Circulation. 1972;46:138-54.

9. Gunnal SA, Wabale RN, Farooqui MS. Morphological variations of papillary muscles in the mitral valve complex in human cadaveric hearts. Singapore Med J. 2013;54:44-8.

10. Victor S, Nayak VM. Variations in the papillary muscles of the normal mitral valve and their surgical relevance. J Card Surg. 1995;10:597-607.

11. Ramsheyi SA, Pargaonkar S, Lassau JP, Acar C. Morphologic classification of the mitral papillary muscles. J Heart Valve Dis. 1996;5:472-6.

12. Gunnal SA, Wabale RN, Farooqui MS. Morphological study of chordae tendinae in human cadaveric hearts. Heart Views. 2015;16:1-12.

13. McCarthy KP, Ring L, Rana BS. Anatomy of the mitral valve: understanding the mitral valve complex in mitral regurgitation. Eur J Echocardiogr. 2010;11:i3-9.

14. Muresian H. The clinical anatomy of the mitral valve. Clin Anat. 2009;22:85-98.

15. Lam JH, Ranganathan N, Wigle ED, Silver MD. Morphology of the human mitral valve. I. Chordae tendineae: a new classification. Circulation. 1970;41:449-58.

16. Hołda MK, Klimek-Piotrowska W, Koziej M, Piątek K, Hołda J. Influence of different fixation protocols on the preservation and dimensions of cardiac tissue. J Anat. 2016;229:334-40.

17. Loukas M, Aly I, Tubbs RS, Anderson RH. The naming game: a discrepancy among the medical community. Clin Anat. 2016;29:285-9.

18. Partridge JB, Anderson RH. Left ventricular anatomy: its nomenclature, segmentation, and planes of imaging. Clin Anat. 2009;22:77-84.

19. Degandt AA, Weber PA, Saber HA, Duran CM. Mitral valve basal chordae: comparative anatomy and terminology. Ann Thorac Surg. 2007;84:1250-5.

20. Perpetua EM, Levin DB, Reisman M. Anatomy and function of the normal and diseased mitral apparatus: implications for transcatheter therapy. Interv Cardiol Clin. 2016;5:1-16.

21. Ranganathan N, Lam JH, Wigle ED, Silver MD. Morphology of the human mitral valve. II. The value leaflets. Circulation. 1970;41:459-67.

22. Rusted IE, Scheifley CH, Edwards JE, Kirklin JW. Guides to the commissures in operations upon the mitral valve. Proc Staff Meet Mayo Clin. 1951;26:297-305.

23. Rusted B, Scheifley CH, Edwards JE. Studies of the mitral valve. I. Anatomic features of the normal mitral valve and associated structures. Circulation. 1952;6:825-31.

24. Ritchie J, Warnock JN, Yoganathan AP. Structural characterization of the chordae tendineae in native porcine mitral valves. Ann Thorac Surg. 2005;80:189-97.

25. Brock RC. The surgical and pathological anatomy of the mitral valve. Br Heart J. 1952; 14:489-513.

26. Victor S, Nayak VM, Dexter L, Farrand RE, Dickson JF. Definition and function of commissures, slits and scallops of the mitral valve: analysis in 100 hearts. Asia Pac J Thorac Cardiovasc Surg. 1994;3:10-6.

27. Layman TE, Edwards JE. Anomalous mitral arcade A type of congenital mitral insufficiency. Circulation. 1967;35:389-95.

28. Klues HG, Roberts WC, Maron BJ. Anomalous insertion of papillary muscle directly into anterior mitral leaflet in hypertrophic cardiomyopathy. Significance in producing left ventricular outflow obstruction. Circulation. 1991;84:1188-97.

29. de Gregorio C. Left ventricular dynamic obstruction by atypical papillary muscle morphology: is this finding so unusual in clinical practice? J Am Soc Echocardiogr. 2007;20:100-1.

30. Smerup M, Funder J, Nyboe C, Høyer C, Pedersen TF, Ribe L, et al. Strut chordal-sparing mitral valve replacement preserves long-term left ventricular shape and function in pigs. J Thorac Cardiovasc Surg. 2005;130:1675-82. 
31. Mestres CA, Bernal JM. Mitral valve repair: the chordae tendineae. J Tehran Heart Cent. 2012;7:92-9.

32. Goetz WA, Lim HS, Pekar F, Saber HA, Weber PA, Lansac E, et al. Anterior mitral leaflet mobility is limited by the basal stay chords. Circulation. 2003; 10:2969-74.
Key Words: papillary muscle, tendinous cords, chordae tendineae, tendinous chords, mitral valve, strut chordae, rough zone, clear zone, basal zone, mitral leaflet, bicuspid valve 